\title{
Impact of Audio Auxiliary Input upon Incidental Vocabulary Acquisition in Foreign Journal Study
}

\author{
Chu Yan ${ }^{*}$, Zhao Yi \\ English Department, Foreign Language School, North China Electric Power University, Baoding, Hebei, China
}

DOI: $\underline{10.36348 / \text { sijll.2020.v03i06.005 }}$

| Received: 19.06.2020 | Accepted: 26.06.2020 | Published: 28.06.2020

*Corresponding author: Chu Yan

\section{Abstract}

Vocabulary learning is an indispensable part of English learning. In recent years, various Foreign Journal Reading Apps have sprung up and become prevalent in China. Accordingly, it has become a choice for many people to expand their vocabulary by learning foreign journals. Based on intensive reading of foreign journals, this paper focuses on the effect of audio auxiliary input mode on Incidental Vocabulary Acquisition of college students. Research shows: compared with single visual input, this input model is more helpful for the participants to acquire vocabulary knowledge in spelling, meaning and application, and improve the efficiency of incidental vocabulary acquisition.

Keywords: Foreign Journal Study, Audio Auxiliary Input, Incidental Vocabulary Acquisition.

Copyright @ 2020: This is an open-access article distributed under the terms of the Creative Commons Attribution license which permits unrestricted use, distribution, and reproduction in any medium for non-commercial use (NonCommercial, or CC-BY-NC) provided the original author and source are credited.

\section{INTRODUCTION}

Vocabulary learning plays a pivotal role in language learning. Vocabulary is the basic unit of language and the cornerstone of sentence composition. In the process of foreign language learning, every skill such as listening, speaking, reading, writing and translating is inseparable from the mastery of vocabulary [1]. Therefore, for many Chinese college students who use English as their second language, the learning and memory of English vocabulary is often the main and difficult point in English learning.

With the rapid development of science and technology, more and more modern science and technology products come into people's vision. Nowadays, Foreign Journal Reading Apps have become a choice for many Chinese college students to learn independently and expand their vocabulary. The author has noticed that among these apps, there's a notable thing in common that almost all the apps provides audio materials in their learning materials. So what role does audio auxiliary input have in Incidental Vocabulary Acquisition in foreign journal learning? What are its specific functions? The author discusses the relevant theory and empirical research on Incidental Vocabulary Acquisition, and conducts an experimental investigation on above questions.

\section{LITERATURE REVIEW \\ Concept of Incidental Vocabulary Acquisition}

The term "Incidental Vocabulary Acquisition" was originally proposed by Nagy, Herman and Anderson [2] on the basis of studying children's learning of mother tongue vocabulary. Later, the scope of this concept has also been expanded. Many scholars at home and abroad have widely applied this concept to second language vocabulary learning through various types of empirical research.

The academic community has not formed a unified definition of "Incidental Vocabulary Acquisition" so far, but through many scholars' interpretations of this concept, the general view is that Incidental Vocabulary Acquisition is compared with intentional vocabulary learning [3, 4]. "Intentional Vocabulary Learning" means that students memorize words deliberately, such as memorizing words by memorizing words on vocabulary book or doing vocabulary exercises; while Incidental Vocabulary Acquisition means that when students complete other tasks (such as intensive reading or intensive listening), their attention is not focused on memorizing the words, but they accidentally acquire the words in the process.

In short, even though the current definition of "Incidental Vocabulary Acquisition" is not clear enough and the concept is not mature enough, as a new research direction of language vocabulary learning, many 
scholars and teachers have studied the subject of "Incidental Vocabulary Acquisition" from many aspects both in the academic and educational fields.

\section{Theories and Research on Incidental Vocabulary Acquisition}

As a popular concept that has been widely accepted a by scholars since the 21st century, the study of "Incidental Vocabulary Acquisition" is still in its infancy. Looking at the existing experimental research on "Incidental Vocabulary Acquisition", the most remarkable feature is that although the research is not thorough and comprehensive enough, the research scope is extremely wide, covering listening, speaking, reading, writing and translating.

According to the survey [5], the empirical research on "Incidental Vocabulary Acquisition" is mostly related to the direction of reading $[6-8,4,9,10$ $11,2,12]$. Therefore, it has been widely accepted that when reading, visual input can promote Incidental Vocabulary Acquisition and thus enlarge vocabulary [13].

\section{METHOD}

\section{Research Purpose}

From above literature review, the scope of research on Incidental Vocabulary Acquisition is relatively wide, and most of them focus on Incidental Vocabulary Acquisition with a single visual input (that is, reading). Compared with the research of visual input, which has had numerous empirical studies and clear and comprehensive conclusion, the research of audio input and audio auxiliary input is almost blank. So there is still a lot of space for researchers to explore. In addition, the combination of audio and visual materials in Foreign Journal Reading Apps, which is widely welcomed by Chinese students, has also inspired and facilitated our research. Therefore, we designed experiments based on different input modes in foreign journal learning to explore the effect and function of Incidental Vocabulary Acquisition under audio auxiliary input mode of Chinese college students, and tried to answer the following questions:

1. Can students acquire English vocabulary with audio input?

2. Does audio auxiliary input contribute to Incidental Vocabulary Acquisition?

3. How does audio auxiliary input affect Incidental Vocabulary Acquisition?

\section{Research Tools}

Questionnaire Stars was used for questionnaire investigation, and SPSS10.0 (Statistical Product and Service Solutions) was used for the analysis of later experimental data.

\section{Research Objects}

In this experiment, a total of 100 juniors from all departments and majors of North China Electric
Power University except English Department were selected. Before the test, these students had similar scores in the CET-4 and College English Course. At the same time, these students did not participate in any English courses in their junior year, which also reduces the interference variables caused by the different teaching progress and their possible impact on the research results.

\section{Research Process}

The study included a test, an experiment, and two interviews. A test refers to the pre-test of the students' basic abilities before the start of the control experiment. An experiment was conducted with audio input as a single variable to give feedback on five consecutive tests to 100 participants during the experiment. The two interviews refer to questionnaire among all participants and face-to-face interviews with randomly sampled participants after the experiment.

The study was conducted in three steps:

Pre-test and Grouping: The investigator conducted a pre-test on the vocabulary size of 100 participants. The pre-test consisted of 50 words randomly selected from the vocabulary list of CET-4 syllabus. The participants were ranked in descending order according to their pre-test scores, and were divided into Group A and Group B by crossing one tester after another in above order. 50 people in Group $A$ as the experimental group used visual and audio materials in the foreign journal learning process, and 50 people in Group B as the control group used only visual materials in the foreign journal learning process.

Controlled Trial: The investigator conducted four rounds of real-time test and one delayed test for participants. Each test was two weeks apart, for a total period of ten weeks.

In the first four tests, each round of the test is based on the following steps:

- Firstly, the investigator distributed learning materials to students in groups A and B relatively (Learning materials are text, text audio, text analysis and analysis audio with moderate difficulty and length selected in the professional Foreign Journal Apps).

- Secondly, all the participants were informed in advance that the vocabulary test will be conducted after the study. Participants complete the material learning within 20 minutes.

- Thirdly, the investigator took back all the learning materials of participants both in groups A and B, and issued vocabulary test papers. The content is the 18 target words selected in the learning materials, including the three aspects of word form, word meaning, and vocabulary application, and each aspect has 6 questions. The test time was 20 minutes. 
The last test is a delayed test of the previous four tests. Using the same test content of the first four test papers, the investigator was meant to examine the test participants' retention of the memory of the 72 target words in the previous four periods. The test time was 60 minutes.

Questionnaire and Interview: After completing the five tests in controlled trial, all the participants were interviewed by questionnaire, and then some students were selected for following up a later face-to-face interview.

\section{DATA AND ANALYSIS}

\section{Experimental Data and Analysis}

As for the processing of experimental data, there is a certain standard in the examination of word form (vocabulary spelling) and the answer to the application of vocabulary (lexical multiple choice). Therefore, when scoring the above two parts, we take 1 point for the correct answer and no score for the wrong answer. However, in the examination of word meaning (the Chinese meaning of words), it is considered that the memory of word meaning cannot be completely consistent during the process of memory, and the guess of some word meaning cannot be completely accurate. Therefore, in order to ensure the scientificity and rationality of scoring, when scoring the part of word meaning, we adopt a grading scoring system, in which we take 2 points for completely correct answer, 1 point for basically correct answer and no score for completely wrong answer.

First, let's take a look at the results of the first four real-time tests of the students in Group A and Group B. Table-1 compares the vocabulary acquisition situation of the students in Group A and Group B according to the three aspects of word form, word meaning and application. It can be seen from the table that the average score of Group A with audio auxiliary input is higher than that of Group B without audio learning materials.

Table-1: Incidental Vocabulary Acquisition in Four Real-time Tests-Comparison of the Mean

\begin{tabular}{|l|l|l|l|l|l|}
\hline & Group & Numbers & Mean & Standard Deviation & Standard Error of the Mean \\
\hline \multirow{3}{*}{ Word From } & $\mathrm{A}$ & 50 & 2.095 & 0.089 & 0.013 \\
\cline { 2 - 6 } & $\mathrm{B}$ & 50 & 2.015 & 0.074 & 0.010 \\
\hline \multirow{3}{*}{ Word Meaning } & $\mathrm{A}$ & 50 & 5.865 & 0.169 & 0.024 \\
\cline { 2 - 6 } & $\mathrm{B}$ & 50 & 5.715 & 0.160 & 0.023 \\
\hline & $\mathrm{A}$ & 50 & 3.275 & 0.251 & 0.035 \\
\cline { 2 - 6 } & $\mathrm{B}$ & 50 & 3.265 & 0.255 & 0.036 \\
\hline
\end{tabular}

Then take a look at the results of the first four real-time tests and the fifth delayed test of participants in Group A and Group B. Table-2 is also the comparative data of the vocabulary acquisition situation of the students in Group A and Group B from the three aspects of word form, meaning and application.

Table-2: Incidental Vocabulary Acquisition in a Delayed Test --- Comparison of the Mean

\begin{tabular}{|l|l|l|l|l|l|}
\hline & Group & Numbers & Mean & Standard Deviation & Standard Error of the Mean \\
\hline \multirow{3}{*}{ Word From } & $\mathrm{A}$ & 50 & 4.840 & 2.587 & 0.366 \\
\cline { 2 - 6 } & $\mathrm{B}$ & 50 & 3.960 & 2.068 & 0.293 \\
\hline \multirow{3}{*}{ Word Meaning } & $\mathrm{A}$ & 50 & 15.860 & 7.261 & 1.027 \\
\cline { 2 - 6 } & $\mathrm{B}$ & 50 & 12.960 & 7.413 & 1.048 \\
\hline \multirow{2}{*}{ Application } & $\mathrm{A}$ & 50 & 9.440 & 3.894 & 0.551 \\
\cline { 2 - 6 } & $\mathrm{B}$ & 50 & 9.260 & 3.944 & 0.558 \\
\hline
\end{tabular}

\section{Interview Content Analysis}

After the completion of the five tests in controlled trial, the investigator conducted a questionnaire survey on the subjective learning feelings of 100 participants. The results of the questionnaire show that $84 \%$ of the participants in Group A thought that audio auxiliary input was very helpful to the learning of foreign journals. $66 \%$ of Group A participants deemed that audio auxiliary input was very beneficial to memorize the spelling of words and help them do better in the word form part during real-time test. And $52 \%$ of the participants in group B reckoned that single text materials made them less sensitive to capture strange or key words, which made them ignore some target words and failed to achieve satisfactory results in the following tests.

In addition, the investigator randomly selected two students from Group A and Group B for a followup interview. This interview showed that from the subjective feelings of participants, two participants in the Group A thought that studying with auxiliary audio materials is more efficient than learning only by text materials, and it is also easier to learn concentrate. When the visual input is supplemented by audio input, the word form can be better remembered through the pronunciation of words. What's more, the meaning and application of vocabulary in the sentence can be strengthened through auditory consolidation. In Group 
B, two participants thought that a single visual input was boring to learn. Although the immediate effect of visual input on vocabulary learning was good during real-time tests, they found that they are apt to forget most word forms because of lacking pronunciationassisted memory. In addition, one of the two participants felt that sometimes he had difficulty in concentrating when reading the article.

\section{CONCLUSION AND SIGNIFICANCE}

This paper studies the phenomenon of Chinese college students' Incidental Vocabulary Acquisition in foreign journal study. The author designs single visual input learning and visual input with audio auxiliary input, and studies the output effect of students' Incidental Vocabulary Learning under such two different input modes. The experimental results show that audio auxiliary input is helpful to the students' Incidental Vocabulary Acquisition in the following three aspects: word from, word meaning and word application, especially in the aspect of word form. In the process of learning foreign journals, audio auxiliary input contributes to more and longer vocabulary memory, which is mainly manifested in the memory of word meaning. This research not only provides an effective strategy for college students to choose their input modes in foreign journal learning, but also provides an empirical support for teachers' audio-visual integration teaching methods in foreign language teaching.

\section{REFERENCES}

1. Dong, Y. (2001). Direct and Indirect Learning of Vocabulary in Communicative Pedagogy. Foreign language teaching and research, (3): 186-192.

2. Nagy, W. E., Herman, P. A., \& Anderson, R. C. (1985). Learning Words from Context. Reading Research Quarterly, (20): 233-253.

3. Laufer, B. (1998). The Development of Passive and Active Vocabulary in Second Language:
Same or Different? Applied Linguistics, 255-271.

4. Laufer, B., \& Hulstijn, J. H. (2001). Incidental vocabulary acquisition in a second language: The construct of task induced involvement. Applied Linguistics, 22(1): 1-26.

5. Gai, S. (2003). Overview of Research on Vocabulary Incidental Acquisition. Journal of PLA Institute of Foreign Languages, (2): 73-76.

6. Dupuy, B., \& Krashen, S. (1993). Incidental Vocabulary Acquisition in French as a Foreign Language. Applied Language Learning, (4): 5563.

7. Elley, W. (1991). Acquiring Literacy in a Second Language: The Effect of Book-Based Programs. Language Learning, 375-411.

8. Joe, A. (1998). What Effects do Text-based Tasks Promoting Generation Have on Incidental Vocabulary Acquisition? Applied Linguistics, (19): 357-377.

9. Li, X. (1998). Effects of Contextual Cues on Inferring and Remembering Meanings of New Words. Applied Linguistics, 401-413.

10. Mason, B., \& Krashen, S. (1997). Extensive Reading in English as a Foreign Language. System, 91-102.

11. Nagy, W. E., Anderson, R. C., \& Herman, P. A. (1987). Learning Word Meanings from Context during Normal Reading. American Educational Research Journal. 237-270.

12. Pulido, D. (2003). Modeling the Role of Second Language Proficiency and Topic Familiarity in Second Language Incidental Vocabulary Acquisition through Reading. Language Learning, 53(2): 233-284.

13. Hulstijn, J. H. (2001). Intentional and Incidental Second Language Vocabulary Learning: A Reappraisal of Elaboration, Rehearsal and Automaticity [A]. In P. Robinson (ed.). Cognition and Second Language Instruction. Cambridge: Cambridge University Press, 258-286. 